\title{
Organizing for sustainability: a cybernetic concept for sustainable renewal
}

\author{
Markus Schwaninger \\ Institute of Management, University of St. Gallen, St. Gallen, Switzerland
}

\begin{abstract}
Purpose - The purpose of this paper is to propose a holistic structural framework for a sustainable renewal that embraces all relevant contexts - individual, organizational, local-regional and worldwide. This should help humanity achieve a future in which society, economy and ecology are united in an evolutionary process based on multiple symbiosis.

Design/methodology/approach - An integrative concept for sustainable renewal is presented, based on Beer's Viable System Model (VSM). The core of that concept is a recursive structure, which organizes the tasks necessary for such renewal. The approach is both analytical and synthetic, proposing a design for the levels of recursion, making up a coherent whole.

Findings - A structure is developed that enables agents at all recursive strata to generate variety in balance with the complexities they face. The organizational architecture based on the VSM, applied to each one of those levels, ensures the necessary and sufficient structural preconditions for the sustainability of the system under study.

Practical implications - The concept proposed here is ready to be used as a blueprint for organizing the efforts for sustainability. It can help decision makers understand that the quest for sustainable renewal is a recursive issue involving all planes, from individual to global.

Originality/value - The quest for the ecological sustainability of planet earth at this stage is not at all successful. The cybernetic model used here organizes the efforts for sustainability in a more effective way than conventional approaches. It also delivers powerful clues for sustainable renewal that are new, in particular a key to the sufficient structural preconditions for sustainability. This paper is an extended version of the Ross Ashby Memorial Lecture delivered by the author at the European Meeting of Cybernetics and Systems Research, Vienna, 24 April 2014, under the title "Organizing for Sustainability".
\end{abstract}

Keywords Sustainability, Systems approach, Viable system model, Organization design, Organizational cybernetics, Recursive structure

Paper type Research paper

\section{Introduction}

Can we restore the sustainability of our planet, and how?

Over the last 200 years, the separation of economics and ecology has led to a profound conflict. The basic notion that the two spheres have a common root - oikos (Greek), meaning household - has been somewhat forgotten. The consequence is an ecological crisis, and the economic crisis we are facing is intrinsically connected with it. Looking forward, we have to find the unity of economic activity and its natural basis again. This paper is a plea for ecological restoration, providing a framework and a path to its accomplishment.

The author is grateful to Dr Felix Gress, Senior Vice President Communications and Public Affairs, Continental Corporation, and Franz Hermann, Mediationsforum Gastein, for providing insights into the structures and history of their organizations. The author also wishes to thank two anonymous reviewers for their helpful comments, and Professor Raúl Espejo for his editorial guidance. 
$\mathrm{K}$

$44,6 / 7$

936

Figure 1.

Dimensions of sustainability
We are caught in a quagmire: the complexities we have created ourselves do not loosen their grip on us. Ross Ashby and Stafford Beer, the eminent cyberneticians, teach us how to deal with the complexity of our world. Fortunately we can revert to their advice about how to cope with our predicament. Therefore, this proposal rests on cybernetics principles.

The Brundtland (1987) Report "Our Common Future”,, which was delivered by the United Nations' World Commission on Environment and Development, defines sustainable development as a "development that meets the needs of the present without compromising the ability of future generations to meet their own needs"[1]. Despite this well-intended declaration, we have not seen much change for the better.

Accordingly, the improvements have been punctual, for example, in the partial greening of European industry. What we see, however, is a deluge of monstrosities - a gigantic squandering of resources, pollution of air, soil and water, depletion of biodiversity, altogether: a disruption of the web of life.

We humans are part of that web, and we carry responsibility for it. In other words, we need better ways of dealing with the ecological challenge. Hence, the question I would like to address in this contribution is: "How must humanity organize itself in order to develop sustainably?"

Sustainability has several dimensions known as the triad "Ecological, Social, Economic". These three spheres interdepend (Figure 1).

Ecological integrity furthers the health of a social system, which then enhances economic prosperity. A thriving economy - as the evidence shows - can become disruptive to the environment (therefore the negative sign on the arrow). That is what we have had in the industrialized world at least since Second World War, and increasingly also in the emerging economies. The dynamics of this system are summarized in the negative signum denoting a balancing loop: this appears to be a self-regulating system, in which damages are eventually compensated.

Yet, the situation is more complex: a healthy environment enhances economic prosperity. Accordingly, injuries to the environment result in dysfunctionalities of the economy. This makes another self-regulating loop, which is supposed to be a good omen. But the appearance deceives: there are delays in the system (marked by the crossbars in Figure 1). Due to these retardations it is likely that the economy thrives even more, until at some point the environment strikes back, unexpectedly and forcefully. Examples have been described, such as the collapse of the Easter Islands, where a whole society was eradicated within very short time, after having destroyed the forests, which were its main resource.

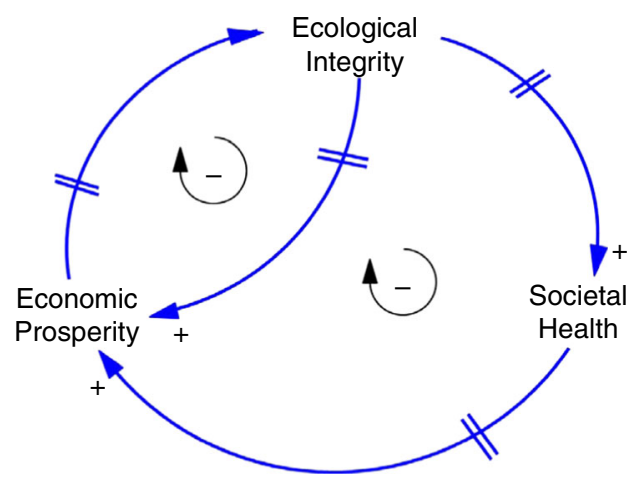


This diagram is a simplification, as additional feedbacks might play a role. My point here is that I will focus on ecological sustainability, which is, in some sense, the most fundamental of the three dimensions. It is interdependent with the other two dimensions, to which I will therefore refer in my analysis as well.

From a long-term perspective, the viability of humanity hinges on a sustainable development. If we want to organize for viability, we have to organize for sustainability. I propose that every viable system is sustainable, but that a sustainable system is not necessarily viable. Further conceptual reflection should examine this proposition. Beyond sustainability this linear interpretation, following the circular logic of Figure 1, and adopting a holistic perspective, "viability" and "sustainability" appear to emerge as eigenbehaviours in a world that provides closure via the time-delayed feedback loops[2].

\section{Choosing a model}

The strongest approach is to choose a model that targets viability and allows us to channel the efforts for sustainability into that quest for viability. In other words, organize sustainability measures so that they enhance the viability of a system.

There are two models that aim at making such viability possible:

- James Grier Miller's Living Systems Theory (Miller, 1978); and

- Stafford Beer's Viable System Model (VSM) (Beer, 1972, 1981, 1984, 1985)[3].

Both of these models have an organismic perspective in common. Both have an enormous potential which has spurred their increasing use in organizations. While Living Systems Theory is older and therefore has been corroborated by a greater number of published empirical studies, the VSM has the advantage of being stronger in its theoretical claim and falsifiability, as well as its diagnostic potency. The claim is that this model specifies the sufficient preconditions for a system to be viable (Beer, 1984). This prerogative reaches much further than the mere reference to "necessary requirements". Even so, the VSM has not been falsified, in other words, it has not been proven to be wrong. Serious attempts to falsify the model have not been successful (Frost, 2005; Crisan Tran, 2006; Schwaninger and Scheef, forthcoming). Therefore, following Popper's Falsification Principle, it can be assumed that it holds. Consequently I shall revert to this model as a guideline.

In the VSM a set of "control mechanisms" is specified, which Beer describes as the necessary and sufficient conditions for the viability of any human or social system.

\section{Outline of the VSM}

A social body is viable if and only if it has a dovetailed structure of regulatory units whose functions and inter-relationships are precisely specified in the theory. I will guide you quickly through the generic structure of the model.

To start with, the basic units: these might be divisions if we look at a firm, nation states if we look at a nation, nations if we look at a continent and continents if we look at the world. These basic units absorb the complexity of the environment they are confronted with.

If we zoom in, this is what we get (Figure 2).

The basic unit (denoted as "agent") adapts itself to the environment by attenuating its complexity and by amplifying its own variety, namely its repertory of behaviours.

This way, environmental complexity and eigen-complexity are brought into balance. That is what Ashby called variety engineering (Espejo and Reyes, 2011). The term 
$\mathrm{K}$ $44,6 / 7$

\section{8}

Figure 2.

Variety engineering with attenuation and amplification of complexity

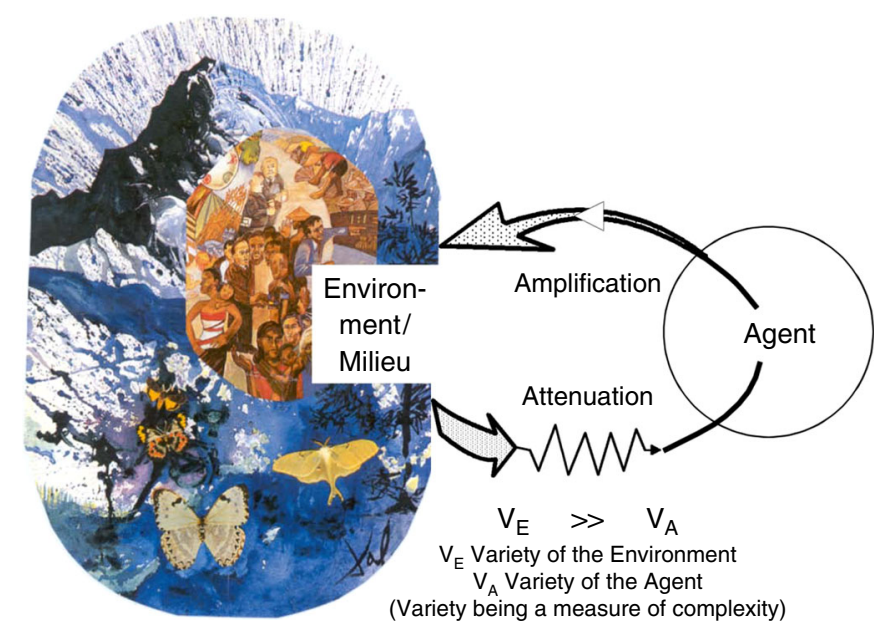

variety here denotes a measure for complexity - the property (potential or actual) of a system to assume many states or behaviours.

Now, let us follow the components of the management system (Figure 3):

- System 1: this is the regulatory capacity of the largely autonomous and mutually adaptive operative basic units, in charge of optimizing the ongoing business. Basic units with their respective management are called primary units. An example: the company's business units.

- System 2: this is the coordination function, which reduces oscillations and enhances self-regulation. For example, the information- and budgeting-systems, internal service-units, standards of behaviour, knowledge-bases, a good deal of communication.
Figure 3.

The viable system model - diagram after Beer, simplified

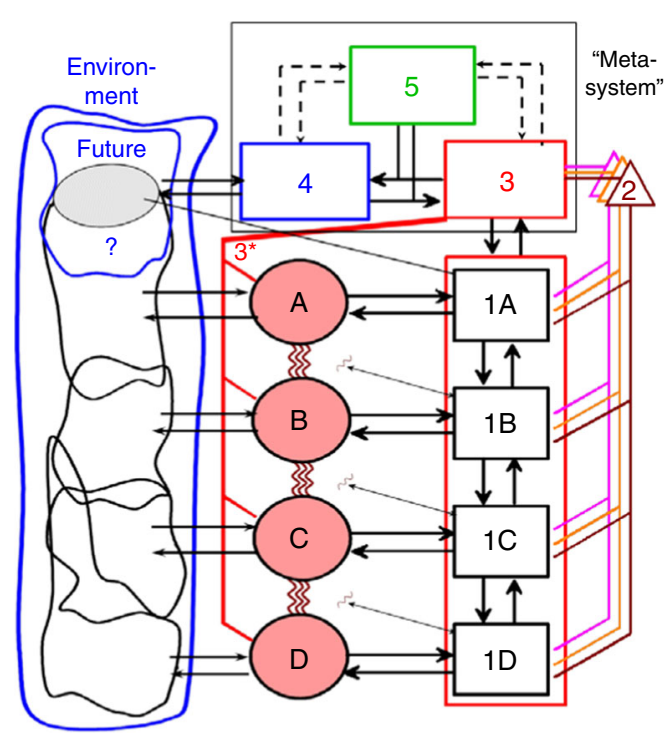


- System 3: in a company we would have the executive corporate management Organizing for here. It provides overall direction, allocation of resources, striving for an overall performance optimum, which is often different from the optima of the sustainability subsystems (primary units).

- System $3 *$ : the auditing channel, where the information flowing through channels 1-3 and 1-2-3, are validated through direct access to the basic units. For example, monitoring and management by walking around, social and cultural activities as well as informal communication.

- System 4: it stands for the long-term orientation to the future and the overall environment. Here we have company development/strategic management, research and development, knowledge creation, etc. System 4 can trigger emergence via self-reference, - the reflection of the system itself and, if indicated, its reframing and redesign.

- System 5: striking the balance between present and future, keeping the internal and external perspectives in proportion. Here we have the supreme norms and values that govern the system - the ethos of the organization or normative management[4].

Systems 1-2-3 represent the operative system, and 3-4-5 the meta-system of the organization.

Why do I take such a complex model? I am using it, because it is the only one that guides us straight to viability!

To sum up: Systems 1, 2 and 3 (including 3*) represent the operative, System 4 (in interaction with 3) the strategic, and System 5 normative management. 3, 4 and 5 together form the meta-system.

The VSM provides a conceptual framework of extraordinary power that can be employed in both modes, diagnosis and design. I have applied it in either way, with my team, to all kinds of social systems: big, small, public and private. Applying the model to a real firm or any other social system brings diagnostic points to the fore, which can change its fate completely. The better the diagnostic points, the greater the chance for a superior organizational design.

The model is of neurophysiological origin. It is homomorphic in relation to the human central nervous system (Figure 4). Humans are the best paragon of viable systems. What Stafford Beer discovered is an isomorphic structure for mapping both social and organismic systems.

After the original works by Stafford Beer, several authors have subsequently provided methodological guidance for the application of the VSM (e.g. Espejo and Harnden, 1989; Espejo et al., 1996; Hoverstadt, 2008; Schwaninger, 2009; Espejo and Reyes, 2011; Pérez Ríos, 2012). In addition, many case studies about uses of the VSM in diverse contexts have been published; an overview can be found in Schwaninger (2009, p. 107f), and Schwaninger and Scheef (forthcoming).

\section{Two principles: autonomy and recursion}

The viability, cohesion and self-organization of a social body depend upon these functions being recursively present at all levels of its organization.

A recursive structure comprises autonomous units within autonomous units. Moreover, a viable social system, e.g. a company, is made up of viable units and is itself embedded in more comprehensive viable units (Figure 5; after Beer 1979, p. 315). 
$\mathrm{K}$

$44,6 / 7$

940

\section{Figure 4.}

The neurophysiological basis of the viable system model

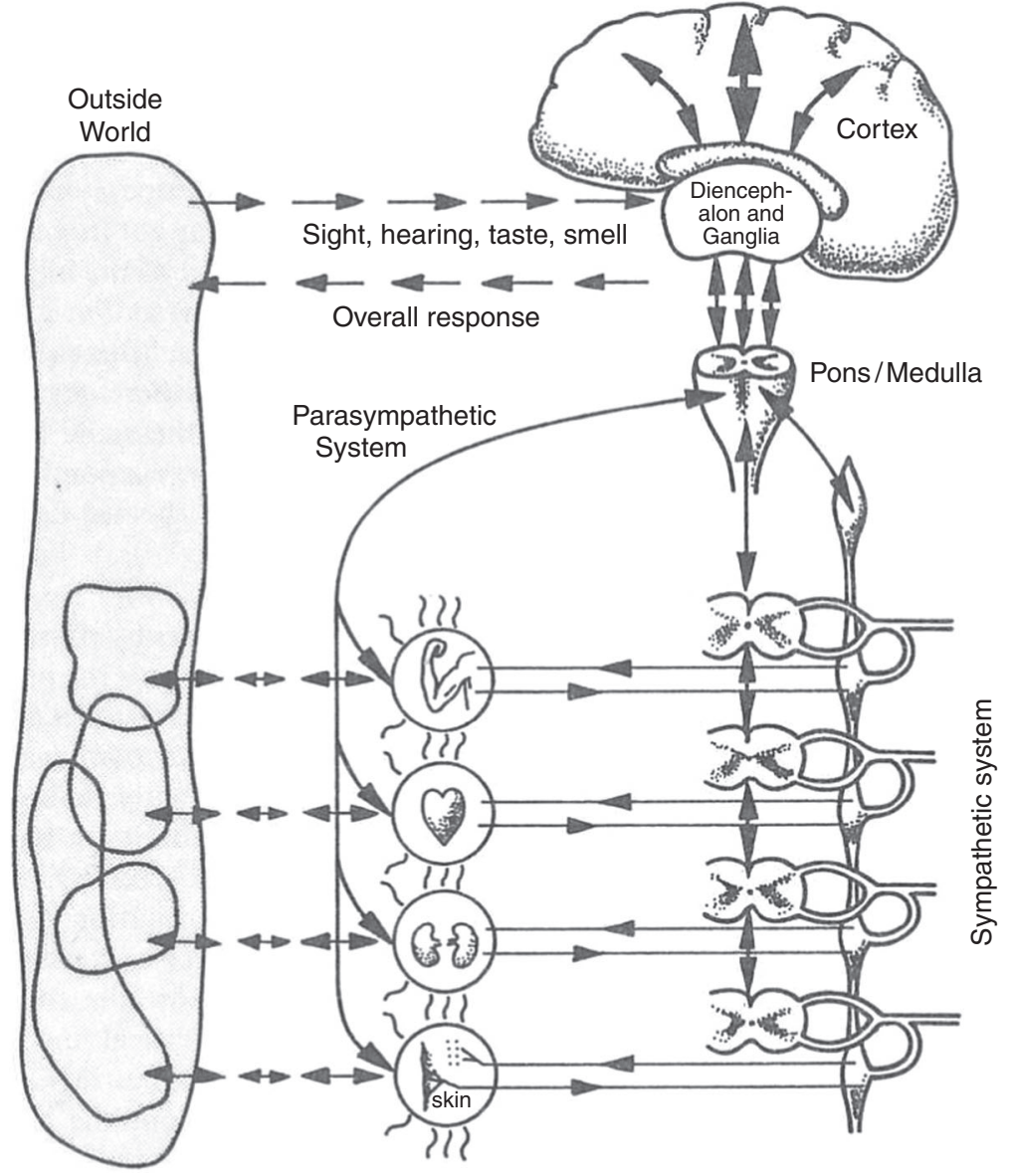

Source: Beer (1981, p. 131)

Each unit, inasmuch as it is producing the organization's task rather than servicing or supporting this production, replicates - in structural terms - the totality in which it is embedded.

So we meet the same structure over and over along the levels of the organization.

Autonomy is basic to the VSM. From Greek "autos" (for self-) and "nomos" (for law) this term refers to the primary unit as a whole being "a law unto itself", as Beer (1981) defined it. The autonomy in question is therefore both a system's freedom and the responsibility to regulate itself. This is the pivot of an organization's adaptation and learning.

In case the challenges confronted exceed the capability of such a primary unit, joining forces becomes necessary. In many cases this can be achieved by a horizontal cooperation. However, it can indicate the necessity of jointly constituting a new unit at a higher level of recursion. For example, municipalities form states and states form nation states.

However the formation of a new organizational unit is not necessarily linked to a merger of all aspects of the activities of the systems. 


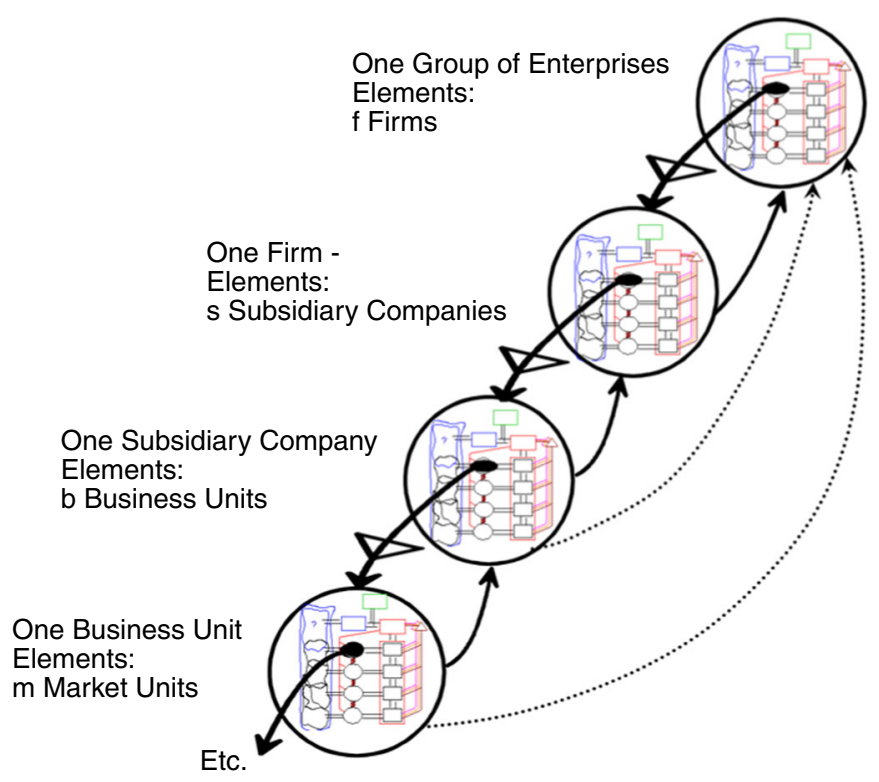

Organizing for sustainability

941

Figure 5.

Recursive structure of the viable system model - example

For example, two or more units can join forces to deal with the ecological challenge in a more prolific way than if they go on their own (Figure 6).

The structure outlined here shows that one and the same organization can function simultaneously both as a sub-system and a super-system within the framework of different recursive organizational dimensions: recursion is a multidimensional concept[5].

With this structure we were very successful in bundling the ecological effort - of a large division in a company of the chemical industry - in a critical and life-threatening phase.

The division in focus is part of that large corporation and is itself composed of several business units (Recursion A). In order to cope with the ecological challenge, the division joined other enterprises from outside, to form an association for that purpose (Recursion B). Additionally, this company was a member of a consortium for research and development (shown in Recursion C). Hence Figure 6 illustrates a junction where a virtual organization is formed[6].

The dimensions of sustainability in Figure 6 imply the simultaneous unfolding into recursive levels of many different units. Such deconvolutions are shown in Figures 5, 7 and 9. Together the unfoldings form a systemic braid where systems on one recursive level are parts of each others' environments while on other levels the same systems interact and form alliances, which act as virtual organizations. How can this complexity be reconciled with the strict distinction between environment and agent (Figure 2)?

In its different identities, one and the same division is not only a member of three different recursions, but also is confronted with the respective environments. When focusing on system Recursion $\mathrm{A}$, the other two $\mathrm{B}$ and $\mathrm{C}$ are at the same time members of $\mathrm{A}$ and parts of its environment. Here, the obstinate quest for unity runs aground on $\mathrm{a}$ paradox: one and the same whole is viable but has different identities[7]. The main point here, which resolves the paradox, is that the interaction at any local level can entail the emergence of new system properties at the level of a greater whole. The aspect of emergence will be taken up again in the next section. 
$\mathrm{K}$ 44,6/7

\section{2}

Figure 6.

Recursive structure, multidimensional

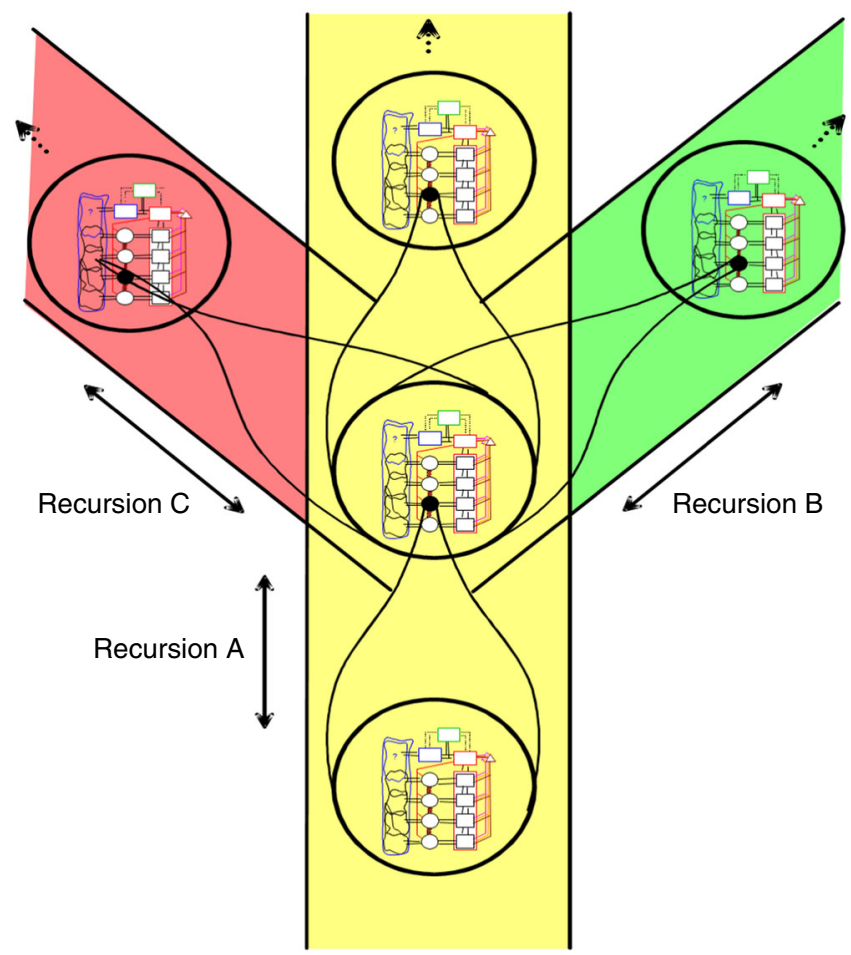

\section{An organizational framework for the pursuit of sustainability}

We can now apply the VSM in support of ecological sustainability. The coming sections are based on earlier work by the author (Schwaninger 2006b, 2008). The difference is that here new cases are presented to support the argument. Since the publication of these early works on the topic, other authors as well have argued for using the VSM as a conceptual framework for the achievement of sustainability (Espinosa et al., 2008; Espinosa and Walker, 2011). Their work is complementary to mine. In comparison, Espinosa and co-authors use different cases, but follow the same line of argument. Their presentations are insightful and they also provide welcome new facets of interpretation. The issue of sustainability is too important to be defended by one author only.

Instead of starting at the global level, we shall begin with the individual agent. One often hears that sustainability starts in the head of the individual that acts according to ecological principles. However, agents exist at different levels, if you look at the world from a system-theoretic perspective. For example, we can identify a whole company as one agent: let us take Interface, leading producer of carpet tiles, a company that excels by its ecological commitments: closed loop products, zero environmental footprint and a restorative approach just to name a few. Ray Anderson, whom I interviewed a few years ago, was the initiator of this orientation[8].

But today, when Interface announces that it wants to be "a corporation that cherishes nature and restores the environment", guided by a "Mission Zero commitment"[9], it speaks with one voice, as one agent. 


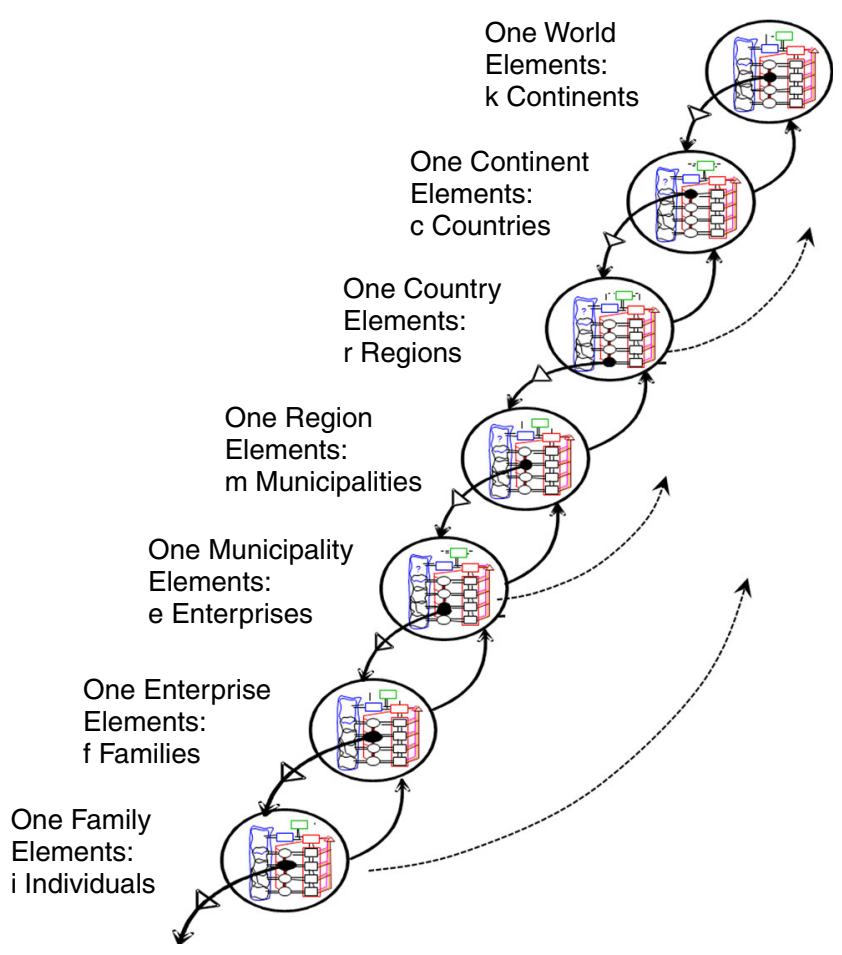

Organizing for sustainability

Also, the aggregated results of the strategies to make this vision come true will be measured and reported in organs of the corporation as a whole. On lower levels of recursion, different divisions, teams or staff members will develop their own views, values and strategies: following the logic "What is my contribution to our mission?"

As we know, strong and viable organizations thrive on that mutual alignment of values, strategies and actions, from bottom to top and from top to bottom.

Hence, we conceive of agents as human or social units, acting as wholes, at different recursive levels of a human or social system. In the context of the quest for sustainability, we can now outline an idealized structure of the multiple agents concerned (Figure 7).

In this scheme, the structure reaches from the level of the individual to the level of the whole world. One might think that the multiplicity of agents forming the system at all of these levels is prohibitive to an endeavour of mapping all of them at once.

Why is this diagram so simple? Because it uses the recursion principle: wholes at multiple strata absorb complexity along the fronts at which that complexity emerges. The reach of this structure is practically infinite. It visualizes that each level has its regulatory issues in their own right. To maintain viability, each agent has to deal with that task of absorbing the specific complexity by which he or she is affected, in accordance with Ashby's Law of Requisite Variety: it says "Only variety can absorb variety”[10].

That is Ashby's advice and it is the instruction for the design which I am presenting. Requisite variety is the nucleus of viability.

Issues of ecological (and social) sustainability arise everywhere, but they vary according to the planes. It does not make sense trying to solve the pothole problem at 
$\mathrm{K}$ $44,6 / 7$

944

the global level, this is a task of every mayor, in each city or village. On the other hand, forbidding a toxic substance is often a national or international issue. But a company can be even faster by interdicting that substance in its own plant or creating an incentive for not using it (e.g. a fine per kilo, as done in a Swiss company). In principle, the approaches to sustainability management need to be customized at the different planes; one single approach would be insufficient. However, the organizational framework is one that provides closure among the multiple strata.

Most affairs can be regulated at the bottom, so that higher levels should only regulate what cannot be taken care of at the lower ones. This corresponds to the principle of subsidiarity[11].

The lines drawn bottom-up symbolize the principle of subsidiarity as well as the participation, mainly in regulatory activities, of higher level bodies. The lines drawn top-down indicate the unfolding of viable systems along different recursive strata.

The principle of recursion multiplies the capacities of complexity absorption. It is applicable ad infinitum, and therein lies its tremendous power. Processes of self-organization arise at each one of the planes, as well as along the vertical lines of the recursive architecture. These processes are distributed and to some degree spontaneous, bringing about the structural and behavioural pattern of a system, within current bounds of system parameters, e.g. goals, values, business model. The main triggers here are fluctuations and feedback.

Can emergence - the emanation of new system properties, namely qualitative changes of identity, - happen in such an organizational context? It can indeed. Emergence can arise from environmental stimuli (major fluctuations[12]), synergy between subsystems and self-reference in the meta-system of the organization (see Section 3). In several cases, companies have reinvented themselves as pioneers of sustainability, with deep implications for their identities, strategies and structures. The Interface and Continental corporations, quoted in this paper, are only two cases in point.

In both transformations, self-reference - in the sense of self-reflexion - played a key role, as a way of higher order learning[13], which often entails system transformation and renewal. In the case of Interface (see above) the founder and CEO of the company experienced an "epiphany" as the crucial stimulus which suddenly and fundamentally changed his outlook and ultimately the company as such: an ecologically virtuous pattern of corporate behaviour surfaced. (Anderson, 1998). At Continental (see below), both enlightenment of the top executive and environmental demands may have synergized to bring about reorientation and a new level of adaptiveness: an ecological orientation, driven by the core values of sustainability and restoration, emerged.

\section{Systemic environmental management}

Now, I would like to share with readers some of the experience accumulated in my research team. We have studied and applied these theoretical foundations over decades and in the most diverse contexts. The three examples outlined in the following are in the diagnostic mode. But they can also be used to draw lessons for the design of viable organizations. The third example could also be understood as a descriptive reconstruction of a process of self-design.

My first example must be limited to one level of recursion only, just to avoid overstretching the case in point. This is an exemplar of a mid-sized industrial company in Switzerland from the chemical industry. 
Let us now walk through the sustainability-related tasks as they are distributed Organizing for across the functions of the VSM:

- System 1: this is about regulation and optimization of ecological management, in the short term, of the basic units. I am referring to the general management provided by the business unit heads and factory managers, ensuring environment- and security-related direction and control.

- System 2: coordinates the ecological efforts across the basic units, provides educational programs, as well as planning and control of ecology-related programmes. The main agents here are a small service unit for sustainability and quality assurance, and a "sustainability circle" with members of different sections. In this System-2-function, the circle is the prime diffusion-medium for ecological consciousness. The instruments used include an ecological accounting system, environment- and quality-related standards of behaviour and knowledge-bases.

- System 3: here we have the overall responsibility for sustainable operations of the company. In charge is one of the three executives of the management board. The sustainability unit (see System 2) reports to this executive.

- System $3 *$ : is about the auditing and monitoring for ecological efficiency, through direct access to the basic units. Ecological audits and special environment-related investigations into the operations are important here, besides informal interactions of higher managers with workers.

- System 4: the long-term orientation concerning sustainability has several contributors, namely research and development and the sustainability circle (in its System 4 function), all coordinated by the sustainability staff. The latter does the systematic work on corporate development and strategy, such as investigation, and modelling. The top executives are part of the strategic management process, and all of these efforts are tied together in the hands of the CEO.

- System 5: determines the identity of the organization, its functions in the environment, incorporating the supreme values and norms, in short, the ecological ethos of the system as a whole (normative management). The CEO is the protagonist and main catalyst of the corporate values seconded by the board. Pertinent instruments are the corporate charter (with values and business mission), and a sustainability vision statement. The corporate charter was elaborated with the participation of employees from all sectors.

This setup gets close to the ideal-type of a VSM-based structure. No wonder, the company is one of the best managed in the country, in ecological terms. By the way, empirical studies indicate that high environmental performance goes hand in hand with superior overall performance, e.g., Meffert and Kirchgeorg (1992, p. 190).

This was the structure for one recursion level, - the company as a whole. The same principles apply to the structures at other recursive planes. Let us just take a brief glance into this matter, and use the case of a larger company, - the Continental Corporation with whom I have been collaborating for many years. Continental is an organization dedicated to mobility and transport, best known for its tires and steering systems.

The management there is convinced that the effort for sustainability is more than environmental protection. It must go beyond end-of-pipe measures and be organized in 
$\mathrm{K}$ $44,6 / 7$

946 a circular fashion (Figure 8). And it must be deeply ingrained in all domains: starting from research and development, supply chain, production and the entire value chain.

Therefore, Continental's approach is convincing: first, the quest for sustainability there is companywide considered a task of each member of the organization. This norm is contained in the leadership principles and practices.

Second, the responsibility for the greening of the firm is anchored throughout the line (Figure 9). At the level of top management to begin with: the ultimate responsibility for the sustainability of the company, in all respects, is with the chairman of the executive board ("CEO") together with the executive board as a whole. The CEO carries the line responsibility for quality and environment (System 3). At his side is a strong service unit called "Corporate Quality and Environment", which has very much a 2-3* function, in terms of the VSM. There is a second related line function for corporate social responsibility, - with the executive board member for human resources (part of System 3). There are also other mechanisms of coordination, such as rules and procedures, not only for quality and environment, but also for security, health, etc.

The long-term issues of sustainability (System 4) are regularly handled by the Corporate Social Responsibility Council. The supreme tenets and principles (System 5) are well documented in corporate values and mission statements. This system is carried down to the divisional recursion. Here again, we find the same structure, in all five divisions (Tires, three Automotive Divisions and Continental Technologies). And the same logic continues further down.
Figure 8.

Circular concept of the value chain (value cycle)

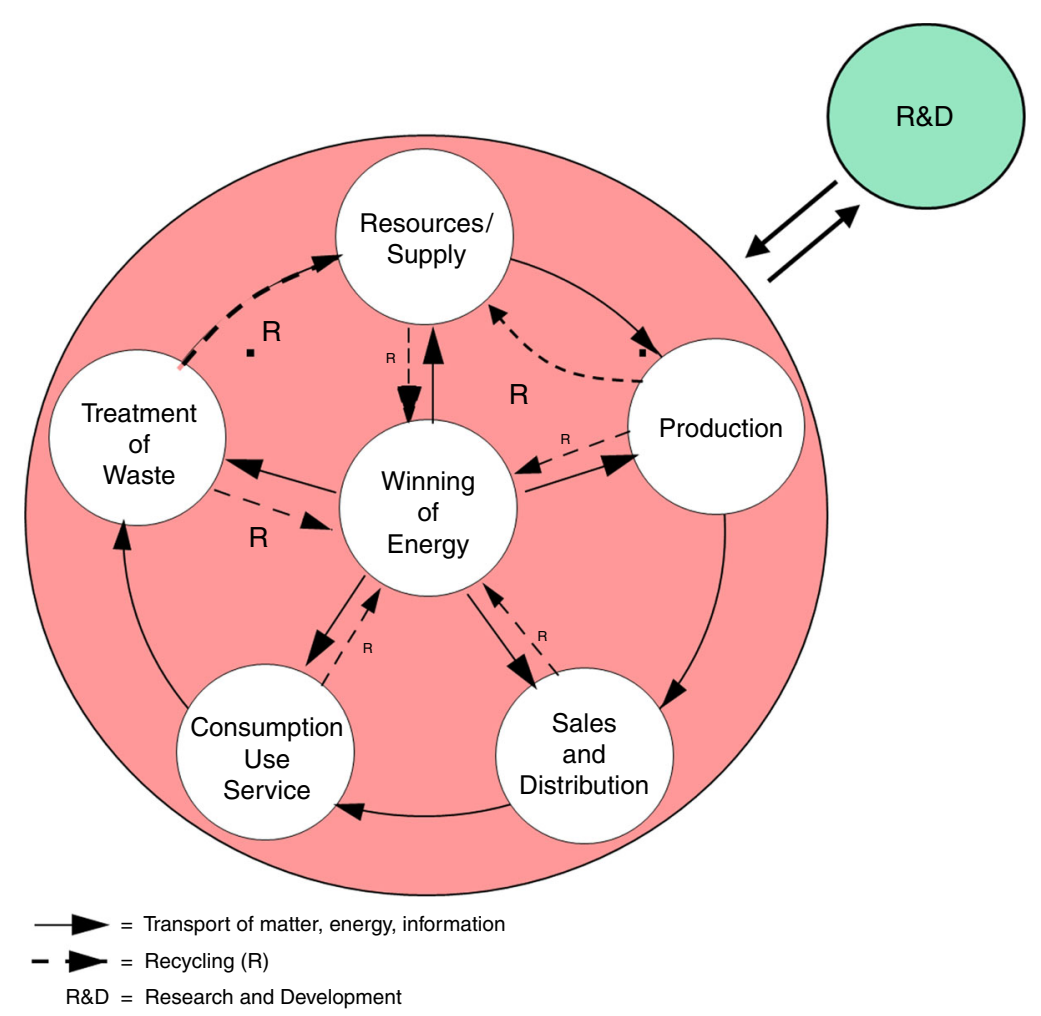




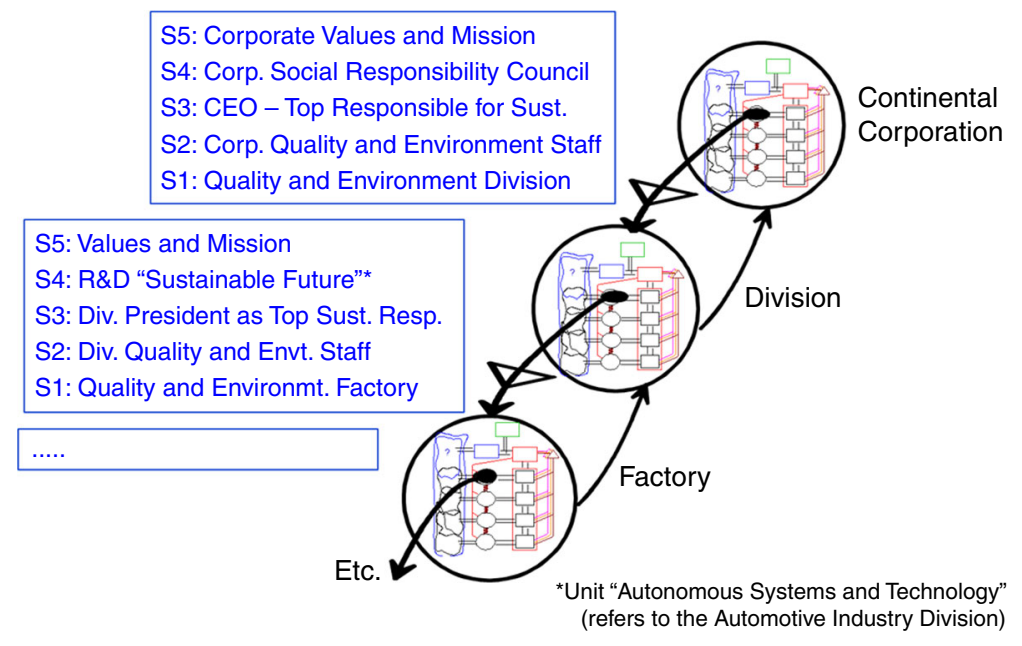

Organizing for sustainability

947

The arrangement of tasks, as outlined, shows what Ashby's Law already taught us: ecological and social responsibility must not be confined to a single person or plane. The issues of these domains transcend boundaries. Hence, coping with them calls for distributed intelligence.

Moving up the ladder of recursions, we could now assess and design the structures for sustainability at the planes of community, region, country, etc. At these levels some no successes have been achieved. Policies of protection are fortunately gaining ground, but often policies of renewal - restoration, systemic redesign and reconstruction - are indicated in addition (Allison, 2012). Finally, far-sighted preventive policies need to be invented to a much greater extent than heretofore.

At this point, I would like to acquaint the reader with a case from a whole region. There, I realized an ecological study based on cybernetics, which turned out to be seminal[14]. Both protection and redesign were accomplished successfully.

The Gastein Valley in Austria is one of the most beautiful alpine valleys. Its three villages have been much procured by tourists in winter and summer, since the middle ages. Around the turn of the millennium, the valley suddenly found its sustainability and viability heavily threatened.

A plan based on the treaties with the European Union envisaged a counter-systemic intervention: the construction of a heavy-duty, high-speed train connection throughout the valley. The level of emissions (mainly noise) would be capable of jeopardizing the traditional tourism and health industry, and the local socio-cultural web. Based on a local initiative, a mediation forum with authorities and all other stakeholders concerned was formed. This forum asked me for advice. The ensuing process of studies and negotiations led to a decision at the level of the Austrian Ministry of Transport, Infrastructure and Innovation, which averted the imminent danger from the valley. Our analysis, from hindsight, shows that, as the process went along, the Gastein Valley organized itself in view of the threat: it evolved a structure for sustainability and viability (Figure 10). A more detailed report about this case can be found in Schwaninger (2012).

The primary units here are the three villages, each one with its management. The meta-system 3-4-5 had not existed at all, and formed itself in face of the challenge: a 
$\mathrm{K}$

$44,6 / 7$

948

Figure 10.

Regional organization for sustainability Gastein valley

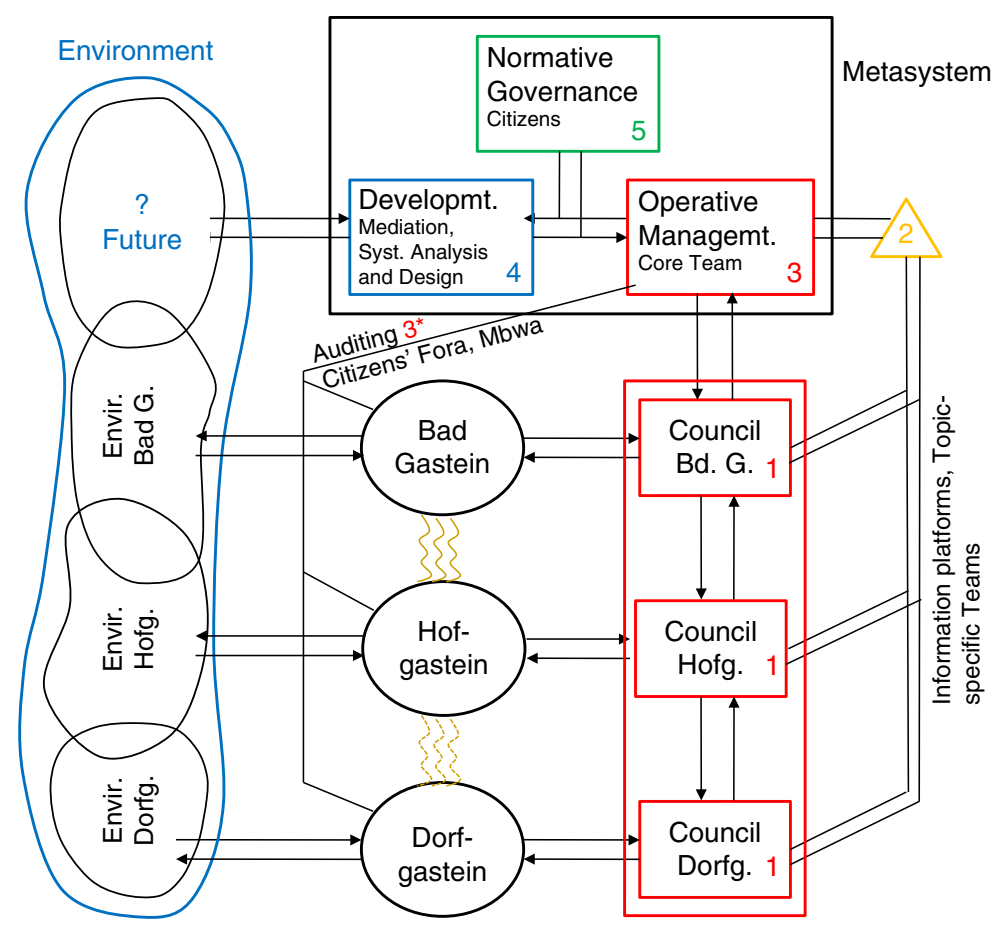

management for the sustainability of the Gastein Valley as a whole. An original aspect of this case is that the management structure is not crafted in the conventional way, but rather in the way of a self-organizing network that emerged in the process, encompassing politicians, professionals, citizens, etc.

This enabled the creation of a concept that was far superior in ecological terms to the original plan of the ministry: more environment friendly, less noisy, more sustainable. That new plan was incorporated into the overall transport policy of the Austrian Ministry of Transportation, Innovation and Infrastructure. This surprising outcome is vital for the valley as a whole. It resulted largely due to this enabling structure of viability and the culture that went with it.

So much for the regional plane.

Carrying on, to the country level, we have at least two great analytical works: one is a design proposal by Stafford Beer (1989) for nations in general. The other is a careful diagnosis of the Swiss political system, by my doctoral student Willemsen (1992). His work analysed some implications for ecology. But, a proposal for both a diagnosis and design for sustainability at the national level remains to be accomplished. What is needed in many countries is a transition to a more effective management framework, by which fragmentation and ineffective regulation for sustainability are overcome.

A main challenge at the level of both regions and countries is the design of System 4, by which the continual presence of a long-term orientation is provided. For that purpose, Future Councils have been proposed and implemented, e.g. in France (Conseil général de l'environnement et du développement durable), Costa Rica (Natural Resources Defense Council), as well as in the regions of Brussels, Montreal and Schleswig Holstein, 
among others. The role of these organs is to warrant a high profile of the long-term view in decision making. The chances to avoid aberrations are better if these councils are in place. According to the current state of research, the ideal version would be a group of seven-12 independent individuals, elected for a longer period, say eight years, with a partial renewal of the body every four years[15]. The strongest instrument for such a council would be a veto right to be overruled only by a qualified majority in parliament.

If we move on to the last recursions, continental and global, we discern great ecological problems but low effectiveness in dealing with them (Simonis, 2005; Mazower, 2012; Goldin, 2013). Namely at the level of the world, a large number of institutions try to regulate something, with mixed results at best. The High Level Political Forum on Sustainable Development, a kind of World Council for the Future, instituted in 2013, could be a step in the right direction of building a more effective System 4 at the global level.

The VSM would be a powerful means for bringing about worldwide sustainability. Given by the need for more effective policies at the international level, a call for a multilevel governance has echoed recently (e.g. Bongardt, 2007; Brunnengräber and Walk, 2007). This is congruent with the postulate for recursive structures in this paper. Therefore, it is also a validation of the goals proposed above, even though the suggested means are not necessarily the same.

Sustainability will not happen if it is merely enforced from the top or exclusively pursued at the level of individuals. If we take a view of the overall recursive design, it becomes apparent that a multilevel approach is needed. The issues must be tackled at each recursive plane. None of these is unimportant or "less important".

Regulations must be focused on the needs of specific planes. A fragmentation of the efforts of regulation is an obstacle to ecological balance. We often hear that the environmental crisis results from a deficient consciousness of citizens. I agree. But the crisis is, in equal measure, the product of a structural deficit in the current organizational and institutional makeup.

\section{Conclusion}

This paper has focused on a burning issue - the ecological predicament of humanity.

Overwhelming complexity is the challenge, but our response is potentially powerful enough: it is a design for requisite variety along a recursive structure of autonomous units. I have outlined a blueprint for organizing efforts for sustainability. Other authors have pursued a comparable approach (Espinosa et al., 2008; Espinosa and Walker, 2011). The present publication lends further emphasis to the aspect of recursion: I have tried to make clear that sustainability is an issue for agents at all levels, from individual to global.

In practical terms, all planes from individual to world need their specific organization for an "ecological management" enabling sustainable development and renewal. Specific kinds of challenges and issues arise at each one of those levels, and that is exactly where they have to be coped with. This way, complexity is absorbed wherever it manifests itself. Processes of self-organization and emergence, triggered largely by self-reference, can emanate at each level and across the strata of the system. These organizational properties should be among the foremost considerations of policy makers when designing a framework for global sustainability.

Overcoming the current structural deficits calls for two things:

- First, better organizational and institutional frameworks for enabling agents at each level to make their contribution. 
$\mathrm{K}$

$44,6 / 7$

950

- Second, measures to enhance the ecological consciousness of citizens and their capacity for becoming environment friendly (last but not least, good frameworks as such should contribute to that environmental consciousness). But ultimately the success of the ecology movement will hinge on people's love and compassion for nature.

Towards the end of this chapter, after all the examples shown and some ex post reflection of the case studies described, the question should be raised about the optimal role of the VSM in real-world interventions. This question addresses the desired guidance that can be provided based on the case studies. The insights gained with these experiences deliver value for similar cases: as in other publications (e.g. Schwaninger, 2006c), the use of the VSM, in the first two cases, underlines its value as a diagnostic device. That speaks for using this model as a framework for organizational diagnosis, and as a powerful alternative to other approaches.

Also the use of the model in the design mode is strongly suggested. The VSM was used only as an ex post vehicle for reflection (diagnostic mode) in the Gastein case, and to a smaller extent also in the other two cases. Given the extraordinary results achieved in that case, it can be concluded cogently that the model could be employed as an instrument of design, in comparable instances, with great leverage.

In sum, the design of organizational contexts supportive of change or problemsolving processes, with the VSM as a frame of reference, is strongly recommended on the grounds of the cases presented here. We are now in a position to emphasize this suggestion, because a recent empirical study strongly supports the theoretical claim of the VSM (Schwaninger and Scheef, forthcoming).

In the cases described here the model was used as a frame of reference by the facilitators. We have realized other studies (e.g. Espejo et al., 1996) of design projects, in which the involved stakeholders of the respective organizations also were familiarized with the VSM. Instead of retaining the VSM as a conceptual tool for the facilitators only, the model was "taught" to people who were affected by its use, i.e. to managers and some staff of the respective firms. This led to transdisciplinary dialogues: as the limitations of colloquial speech were overcome, the conversations about organization became deeper and stakeholders could contribute more to the changes brought about. I believe that this is a potentially fertile approach, but it should be examined systematically in future research.

Stafford Beer's VSM was inspired by Ross Ashby - the two men were colleagues and friends. The model makes use of Ashby's Law of Requisite Variety: at each recursive level of the organization, the agents absorb the complexity as it unfolds. This principle is as powerful as it is simple.

The VSM has not been falsified yet. But that is not enough, it needs to be applied. It would be a sin not to use it for the betterment of the human condition. We need to work for the dispersion of that model. For example, I keep teaching people how to make good use of it. Hence, I am now addressing, in particular, the young people: you will not run out of work!

\section{Notes}

1. Ben-Eli (2012) provides a complementary definition which frames the concept of "sustainability" as "a dynamic equilibrium in the processes of interaction between a population and the carrying capacity of its environment such, that the population develops to express its full potential without producing irreversible adverse effects on the carrying capacity of the environment upon which it depends". 
2. I gratefully owe this interpretation to one of the anonymous reviewers.

3. A third candidate, Aubin's (1997) "Viability Theory", is not dealt within detail here. It is purely formal and algorithmic in character, and eludes the purpose of this contribution. See also: Adam, 2000, and Schwaninger, 2006a.

4. In addition, certain alert devices can always be identified in viable systems. Beer (1985, p. 133) calls them "algedonic signals" (from Greek "algos" - pain and "hedos" - pleasure). These warning systems decide if signals of imminent danger have to be sent directly up to System 5 . This component will not be analysed further in the present contribution.

5. An insightful example of a multidimensional recursion is given by Leonard (1989).

6. The topic of virtual organizations in connexion with the VSM was taken up in Schwaninger (2009, p. 91ff).

7. It would reach beyond the possibilities of this paper to discuss in depth whether this is an identity oscillation - similar to the imaginary values discussed by Spencer-Brown (1969, p. 99) - or what I would call a "multi-identity", i.e., a kind of multiple self at the level of organizations.

8. The path of Ray Anderson to ecologically committed entrepreneurship is documented in Anderson (1998).

9. Corporate homepage: www.interfaceglobal.com/Company/Mission-Vision.aspx (accessed January 8, 2015).

10. Ashby's original wording was: "Only variety can destroy variety" (Ashby, 1956). Beer inserted the more insightful verb "absorb” (Beer, 1979).

11. Subsidiarity is an organizing principle according to which a central authority should have a subsidiary function, performing only those tasks which cannot be performed effectively at a more immediate or local level (Oxford English Dictionary). In other words, "a matter ought to be handled by the lowest, smallest and least centralized authority capable of addressing that matter effectively" (http://en.wikipedia.org/wiki/Subsidiarity, accessed 22 May 2014).

12. In this context, Prigogine's theory of dissipative systems, with its concept of "order through fluctuation", is crucial: nonlinear systems under conditions far from equilibrium can pass over into new situations, in which fluctuations play a central role. These fluctuations can force the system to leave a given macroscopic state (Prigogine, 1976).

13. The distinctions made here are on the one hand between first order learning, - the learning through error correction, - and second-order learning, via changes of goals and other crucial parameters, which can involve a complete redesign of a system. In addition, meta-learning, or what Bateson (1973) called "deutero-learning" (pp. 140ff.), denotes the aspect of learning to learn (better).

14. More details about this case are available in Schwaninger $(2012,2013)$.

15. This design is proposed by the Swiss Foundation Future Council (Unteregger, 2006; Sieber, 2014). A similar, more extensive proposal for an "Ecological Council" is presented by Binswanger and Wepler (2009).

\section{References}

Allison, S.K. (2012), Ecological Restoration and Environmental Change Renewing Damaged Ecosystems, Routledge, London.

Anderson, R.C. (1998), Mid-Course Correction. Toward a Sustainable Enterprise: The Interface Model, Chelsea Green Publishing, White River Junction, VT. 
$\mathrm{K}$ $44,6 / 7$

952

Ashby, W.R. (1956), An Introduction to Cubernetics, Chapman \& Hall, London.

Aubin, J.-P. (1997), Viability Theory, Springer, Berlin and New York, NY.

Bateson, G. (1973), Steps to an Ecology of Mind, Paladin Books, London.

Beer, S. (1979), Heart of Enterprise, Wiley, Chichester.

Beer, S. (1981), Brain of the Firm, 2nd ed., Wiley, Chichester, (First edition: 1972).

Beer, S. (1984), "The viable system model: its provenance, development, methodology and pathology", Iournal of the Operational Research Societv, Vol. 35 No. 1, pp. 7-25.

Beer, S. (1985), Diagnosing the System for Organizations, Wiley, Chichester.

Beer, S. (1989), "National government: disseminated - regulation in real time or "how to run a country'”, in Espejo, R. and Harnden, R.J. (Eds), The Viable System Model - Interpretations and Applications of Stafford Beer's VSM, Wiley, New York, NY, pp. 333-360.

Ben-Eli, M.U. (2012), "The cybernetics of sustainability: definition and underlying principles", in Murray, J., Cawthorne, G., Dey, C. and Andrew, D. (Eds), Enough for All forever: A Handbook for Learning about Sustainability, Common Ground Publishing, University of Illinois, Champaign, IL, pp. 255-268.

Binswanger, H.C. and Wepler, C. (2009), "Ein Ökologischer Rat als Vertreter der Interessen künftiger Generationen”, in Binswanger, H.C. (Ed.), Vorwärts zur Mässigung. Perspektiven einer nachhaltigen Wirtschaft, Murmann, Hamburg, pp. 207-213.

Bongardt, D. (2007), "Multi-level governance und Europäische Umwelpolitik. Akteurskonstellationen und Inteaktionen im politischen System der Europäischen Union”, in Brunnengräber, A. (Ed.), Multi-Level-Governance : Klima-, Umwelt- und Sozialpolitik in einer interdependenten Welt, Schriften zur Governance-Forschung; Bd. 9. Nomos, Baden-Baden, pp. 49-74.

Brundtland, G.H. (1987), Our Common Future. The World Commission on Environment and Development, Oxford University Press, Oxford.

Brunnengräber, A. and Walk, H. (Eds) (2007), Multi-Level-Governance: Klima-, Umwelt- und Sozialbolitik in einer interdependenten Welt. Schriften zur Governance-Forschung ; Bd. 9, Nomos, Baden-Baden.

Crisan Tran, C.I. (2006), "Beers Viable System Model und die Lebensfähigkeit von Jungunternehmen: eine empirische Untersuchung", PhD Dissertation No. 3201, University of St. Gallen, St. Gallen.

Espejo, R. and Harnden, R.J. (Eds) (1989), The Viable System Model - Interpretations and Applications of Stafford Beer's VSM, Wiley, New York, NY.

Espejo, R. and Reyes, A. (2011), Organizational Systems. Managing Complexity with the Viable System Model, Springer, Berlin.

Espejo, R., Schuhmann, W., Schwaninger, M. and Bilello, U. (1996), Organizational Transformation and Learning. A Cybernetic Approach to Management, Wiley, Chichester.

Espinosa, A. and Walker, J. (2011), A Complexity Approach to Sustainability. Theory and Application, Imperial College Press, London.

Espinosa, A., Harnden, R. and Walker, J. (2008), “A complexity approach to sustainability Stafford Beer revisited”, European Iournal of Operational Research, Vol. 187 No. 2, pp. 636-651.

Frost, B. (2005), "Lebensfähigkeit von Communities of Practice im organisationalen Kontext", $\mathrm{PhD}$ Dissertation No. 3120, University of St. Gallen, St. Gallen.

Goldin, I. (2013), Divided Nations. Why Global Governance is Failing, And What We Can Do About It, Oxford University Press, Oxford.

Hoverstadt, P. (2008), The Fractal Organization. Creating Sustainable Organizations with the Viable System Model, Wiley, Chichester. 
Leonard, A. (1989), “Application of the VSM to commercial broadcasting in the United States”, Organizing for in Espejo, R. and Harnden, R. (Eds), The Viable System Model, Interpretations and. Applications of Stafford Beer's VSM, Wiley, Chichester.

Mazower, M. (2012), Governing the World: The History of an Idea, Penguin Press, New York, NY.

Meffert, H. and Kirchgeorg, M. (1992), Marktorientiertes Umweltmanagement: Grundlagen und Fallstudien, Poeschel, Stuttgart.

Miller, J.G. (1978), Living Systems, McGraw-Hill, New York, NY, (re-published: University Press of Colorado, Niwot, Colorado, 1995).

Pérez Ríos, J. (2012), Design and Diagnosis for Sustainable Organizations: The Viable Svstem Method, Springer, Berlin.

Prigogine, I. (1976), "Order through fluctuation: self-organization and social system", in Jantsch, E. and Waddington, C.H. (Eds), Evolution and Consciousness: Human Systems in Transition, Addison-Wesley, London, pp. 93-133.

Schwaninger, M. (2006a), “Theories of viability: a comparison”, Svstems Research and Behavioral Science, Vol. 23 No. 3, pp. 337-347.

Schwaninger, M. (2006b), "The quest for ecological sustainability: a multi-level issue", in Trappl, R. (Ed.), Cybernetics and Systems, Vol. 1, Austrian Society for Cybernetic Studies, Vienna, pp. 149-154.

Schwaninger, M. (2006c), "Design for viable organizations: the diagnostic power of the viable system model”, Kvbernetes, Vol. 35 Nos 7/8, pp. 955-966.

Schwaninger, M. (2008), "Organising for sustainability”, International Iournal of Applied Systemic Studies, Vol. 2 Nos 1/2, pp. 40-48.

Schwaninger, M. (2009), Intelligent Organizations: Powerful Models for Systemic Management, 2nd ed., Springer, Berlin.

Schwaninger, M. (2012), "Making change happen: recollections of a systems professional", Kvbernetes: The International Iournal of Systems \& Cubernetics, Vol. 41 Nos 3/4, pp. 348-367.

Schwaninger, M. (2013), "An integrative systems methodology for dealing with complex issues”, in Zelger, J., Müller, J. and Plangger, S. (Eds), GABEK VI - Sozial verantwortliche Entscheidungsprozesse, StudienVerlag, Innsbruck, pp. 177-196.

Schwaninger, M. and Scheef, C. (forthcoming), "Can the theoretical claim of the viable system model (VSM) be upheld? An empirical study".

Sieber, F. (2014), "Monsieur Avenir. Robert Unteregger will mit Zukunftsräten das langfristige Denken in Politik und Gesellschaft verankern", Neue Zürcher Zeitung 5. August, pp. 11.

Simonis, G. (2005), "Weltumweltpolitik: Erweiterung von staatlicher Handlungsiahigkeit durch Global Governance?", in Behrens, M. (Ed.), Globalisierung als politische Herausforderung: Global Governance zwischen Utopie und Realitiit. Governance, Vol. 3, VS Verlag fiir Sozialwissenschaften, Wiesbaden, pp. 313-344.

Spencer-Brown, G. (1969), Laws of Form, Dutton, New York, NY.

Unteregger, R. (2006), "Future councils - an institutional tool to make long-term politics possible”, in Jávor, B. and Rácz, J. (Eds), Do We Owe them a Future? The Opportunities of a Representation for Future Generations in Europe, Védegylet, Budapest, pp. 130-141.

Willemsen, M.H. (1992), 1st die Schweiz ein lebensfiihiges System? Kybernetische Diagnose des schweizerischen Politischen Systems, Riiegger, Chur/Ziirich. 
$\mathrm{K}$

$44,6 / 7$

954

\section{Further reading}

Adam, M. (2001), "Lebensfähigkeit sozialer Systeme: Stafford Beer's Viable System Model im Vergleich”, PhD Thesis No. 2442, University of St. Gallen, St. Gallen.

\section{About the author}

Markus Schwaninger, a Professor Em. at the University of St. Gallen, Switzerland. His research is focused on the management of complex dynamic systems, with a methodological emphasis on organizational cybernetics and system dynamics. Research projects are related to organizational intelligence, model-based management, the design, transformation and learning of organizations and systemic issues of sustainability. Mandates: Director of WOSC - the World Organization of Systems and Cybernetics, and Managing Editor, System Dynamics Review. Professor Markus Schwaninger can be contacted at: Markus.Schwaninger@unisg.ch 